\title{
Spatial dependency of groundwater quality in Benin City, Edo State, Nigeria using semi-variogram models
}

\author{
Maryann Ogoamaka Ezugwu 1, ${ }^{*}$ and Eguakhide Atikpo ${ }^{2}$ \\ ${ }^{1}$ Department of Civil Engineering, College of Engineering, Igbinedion University, Okada, Edo State, Nigerian. \\ 2 Department of Civil Engineering, Faculty of Engineering, Delta State University, Abraka. Delta State, Nigeria,
}

World Journal of Advanced Engineering Technology and Sciences, 2021, 02(02), 029-041

Publication history: Received on 27 March 2021; revised on 30 April 2021; accepted on 02 May 2021

Article DOI: https://doi.org/10.30574/wjaets.2021.2.2.0034

\begin{abstract}
Water quality is a worldwide concern especially water for human consumption. Regular monitoring and tools should be developed, to ensure continuous assessment of the level of concentration of chemical constituents prevalent in water. This will guide against health dangers and risks associated with water of low quality. The research focus on using semivariogram models to measure the degree of spatial dependency of sampled boreholes for prediction of the concentration of water quality parameters at un-sampled locations because of the cumbersome nature of assessing the whole boreholes in Benin City. One hundred and ten (110) different domestic boreholes were systematically sampled and analyzed in laboratory for determination of the concentration of some chemical water quality parameters which include Electrical Conductivity (EC), Total Dissolve Solids (TDS), Bicarbonate (HCO3), Sodium (Na), Potassium (K), Calcium (Ca), Magnesium (Mg), etc. Laboratory examination of boreholes water quality parameters were carried out in wet and dry seasons. Geographical locations of sampled boreholes were also determined. The obtained experimental results were utilized in investigating the spatial structure of the boreholes using semi-variogram models which include spherical, exponential, Gaussian etc. Exponential model was the most fitted model. The borehole water quality parameters exhibited high degree of spatial dependency in EC, TDS, $\mathrm{HCO}, \mathrm{Na}, \mathrm{K}, \mathrm{Ca} . \mathrm{Mg}, \mathrm{Cl}, \mathrm{P}$, and NO3 in both seasons with $\frac{C n}{C}$ ratio $<25 \%$ therefore, interpolation technique can be employed to produce spatial variation quality map of boreholes in Benin City as a monitoring technique to detect contamination or changes in water quality.
\end{abstract}

Keywords: Water quality; Semi variogram models; Spatial dependency; Prediction

\section{Introduction}

Utilization of water by humans cannot be stopped because water is an essential liquid for survival, so much desired in many spheres of lives and activities. The quantity and quality matter a lot in human developments and progress. Access to clean water and sanitation is one of the major goals of United Nation for sustainable developments. The shocking epitome of water quality lies on its impacts and health implications on humans when ingested or indirectly in contact with a contaminated water. There is need for assessment and continuous monitoring of water quality especially domestic boreholes which are the major sources of water supply in Benin City, due to the non-functioning of state water cooperation. It may be cumbersome to investigate water quality of all domestic boreholes in the city, therefore, it is important to employ some spatial interpolation techniques. Spatial interpolation is a technique utilized with observed values on earth surface to estimate and make prediction of values in un-sampled locations within the same area. This spatial interpolation assumes that there is a degree of similarities or attributes between points close to each other [1]. This degree of similarity is otherwise known as spatial dependency. Degree of spatial dependency that exists between observations are expected to be similar to each other, than to distant observations [2]. This investigation in boreholes

\footnotetext{
* Corresponding author: Maryann Ogoamaka Ezugwu

Department of Civil Engineering, College of Engineering, Igbinedion University, Okada, Edo State, Nigerian.
} 
water quality parameters employs the use of semi variogram models to provide model parameters that are used to measure spatial dependency. If the dependency is higher, an accurate variation map depicting boreholes water quality for the entire area can be produced. The concentration values of boreholes water quality parameters sampled within Benin City were investigated to determine its degree of spatial dependency for predicting values in un-sampled borehole points. The inhabitants of Benin-City, Nigeria depend on water from rivers and streams, rain water and boreholes to meet their domestic and industrial needs [3]. Groundwater is one of the most sources exploited for human consumption $[4,5]$. In Benin City, water demand had increased as a result of increase in population, urbanization, industrial and agricultural activities, etc. Thus, the quest for alternative sources to satisfy water demand has led to the indiscriminate construction of boreholes by individuals as coping strategy without any concern on the quality of water abstracted. The quality of water suitable for drinking must be free of pathogenic organisms and dissolved contaminants. Some of the domestic borehole owners have no knowledge of water quality and have never engaged in laboratory determination of borehole water quality. Therefore, it is cumbersome to determine all the domestic borehole in Benin City to assess their quality. Semivariogram models were employed to ascertain the degree of spatial dependency of sampled boreholes quality for determination of un-sampled boreholes water quality within the study area. Semivariogram is one of the significant functions to indicate spatial correlation in observations, measured at sample locations [6]. Semivariograms can be fitted with many models which include circular, spherical, exponential, qaussian, power, rational quadratic, Sine hole effect, K-bessel, J-bessel and stable. The Fitted semivariogram model for each of the water quality parameter provide information referred to as model parameters which are used to measure the degree of spatial dependency of sampled borehole points as a result of distance between them. The model parameters are the range (a), nugget $(\mathrm{Cn})$ and sill (C). The ratio of Nugget to Sill $\left(\frac{C n}{C}\right)$ measures the degree of spatial structure (dependency) of a water quality parameter [7]. If the ratio is less than $25 \%$, the variable has strong spatial dependence; between $25 \%$ and $75 \%$, the variable exhibit moderate spatial dependence, and greater than $75 \%$, the variable shows only weak spatial dependence and cannot be relied upon to make prediction of concentration of other un-sampled location [6, 7]. The nugget, the range and the sill are shown in Figure 1.

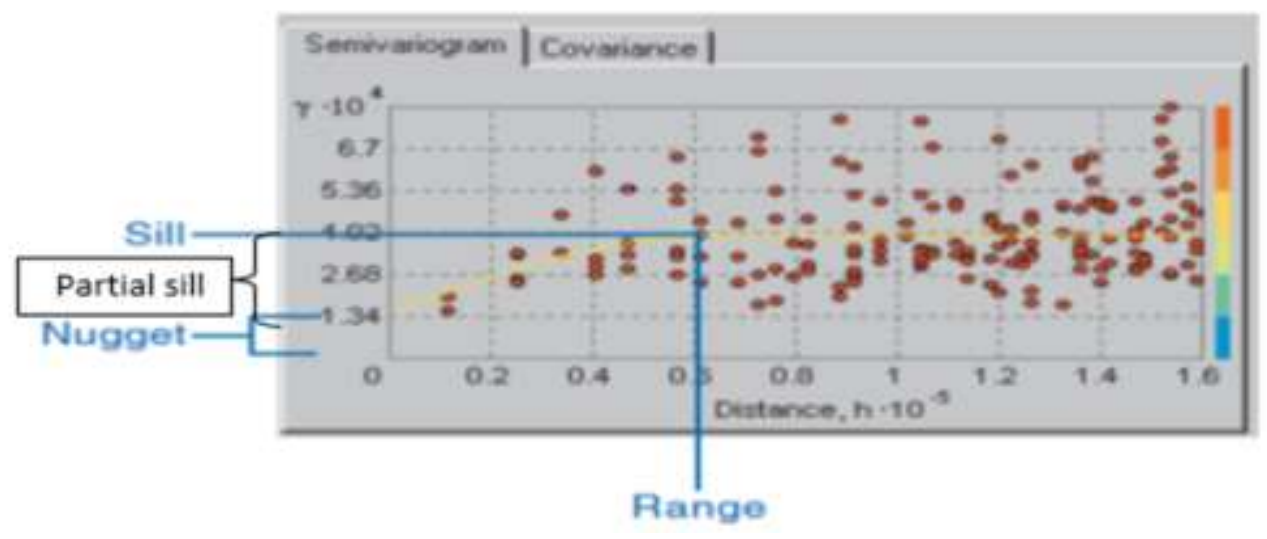

Figure 1 Modified Semivariogram depicting range, sill, and nugget effect [8].

Some of the semi-variogram mathematical models for investigation of spatial dependency of parameters [1,9] include the following:

$$
\begin{gathered}
\text { Spherical: } \quad \gamma(h)=\left\{\begin{array}{l}
\text { if } h=0 \\
c_{n}+\sigma\left(1.5\left(\frac{h}{a}\right)-0.5\left(\frac{h}{a}\right)^{3}\right) \\
\text { if } a<h
\end{array} \text { if } 0<h \leq a\right. \\
\text { Circular: } \gamma(h)= \begin{cases}c_{n}+\sigma\left(1-\frac{2}{\pi} \cos ^{-1}\left(\frac{h}{a}\right)+\sqrt{1-\frac{h^{2}}{a^{2}}}\right) & \text { if } h \leq a \\
c & \text { if } h>a\end{cases} \\
\text { Exponential: } \quad \gamma(h)=c_{n}+\sigma\left(1-\exp \left(\frac{-h}{a}\right)\right)
\end{gathered}
$$


Gaussian: $\quad \gamma(h)=c_{n}+\sigma\left(1-\exp \left(\frac{-h^{2}}{a^{2}}\right)\right)$

Sine hole effect: $\quad \gamma(h)=c_{n}+\sigma\left(1-\frac{\sin (\pi \mathrm{h} / \mathrm{a})}{\pi \mathrm{h} / \mathrm{a}}\right)$

Where, $\gamma(h)=$ semivariogram model

$\mathrm{h}=$ lag distance, $\mathrm{c}_{\mathrm{n}}=$ nugget effect,

$a=$ range (the distance at which the semivariogram reaches the sill)

$\sigma=$ partial sill

$c=$ sill (consists of the nugget effect and the partial sill) i.e., $c=c_{n}+\sigma$

Models provide information about the spatial structure. There is need for cross validation of models to choose the best that suits a particular chemical water quality data. The cross validation criterions for choosing the best model $[6,10]$ are; the Mean Error (ME) and Mean Standardized Errors (MSE) should be close to 0 which indicate that the predictions were not biased but centred on the measured values; the Root Mean Square Error (RMSE) and Average Standard Error (ASE) should be as small as possible and close to each other. These indicate how closely the models predict the measured values and the variability in prediction are well assessed; the Root Mean Square Standardized Error (RMSE) should be close to one (1) indicating that the standard errors are accurate. The chemical parameters analyzed have relative importance in the overall quality of water for human consumption [11]. Their concentration in water indicates the degree of pollution or purity of the water source for drinking purposes.

\section{Description of study area}

Benin City is one of the ancient cities and the capital of Edo State in Nigeria. Erah et al., [12] reported that, it has an area coverage of $500 \mathrm{~km}^{2}$ bounded by $6^{\circ} 06^{\prime} \mathrm{N}$ to $6^{\circ} 30^{\prime} \mathrm{N}$ and $5^{\circ} 3^{\prime} \mathrm{E}$ to $5^{\circ} 45^{\prime} \mathrm{E}$ coordinates. It is about $40.2 \mathrm{~km}$ North of the Benin river and $321.8 \mathrm{~km}$ East of Lagos. The study area experiences wet season (March - October) and dry season (November - February). A base map of the study area is presented in Figure 2.

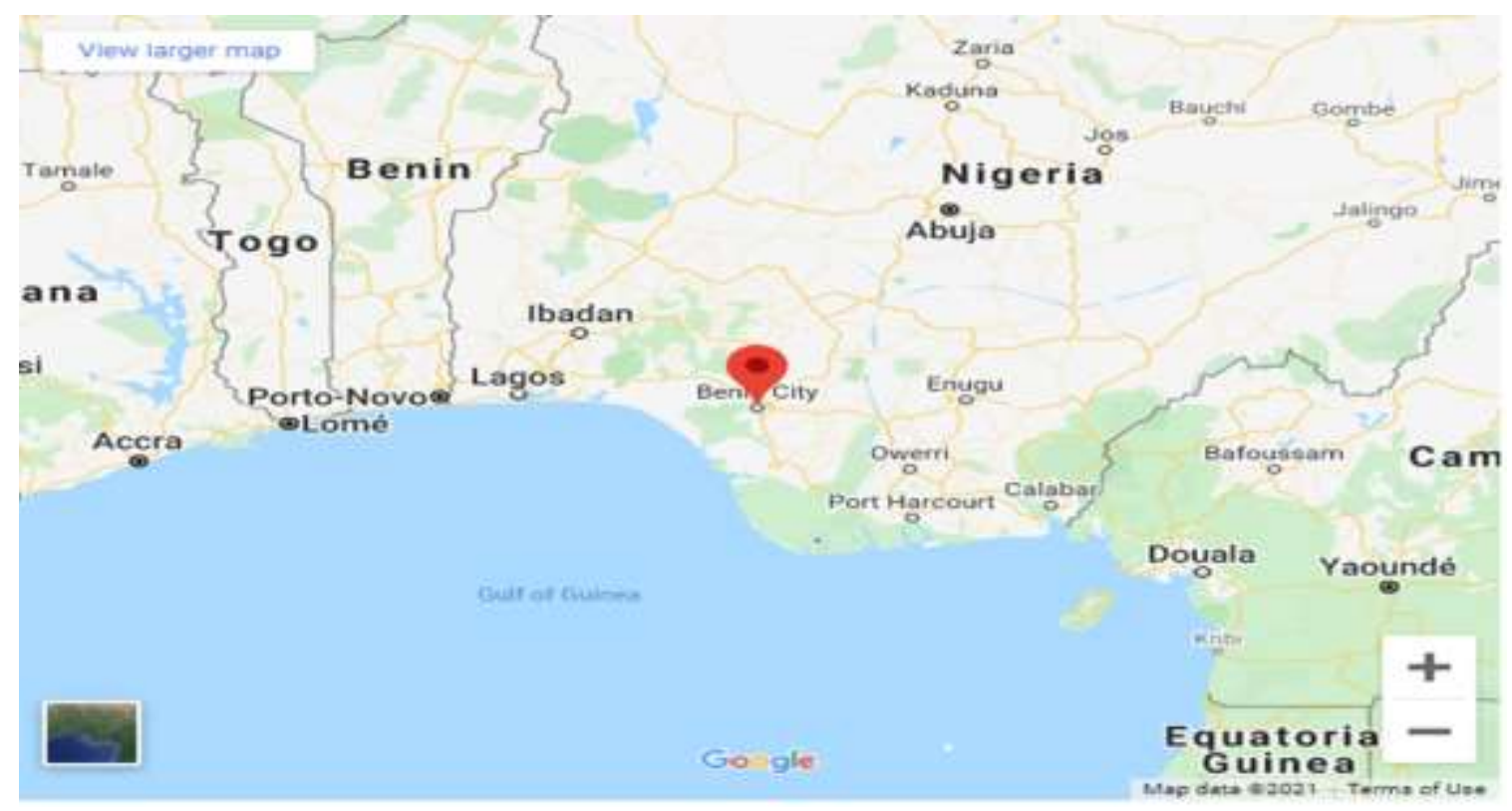

Figure 2 Location Map of the Study Area in Nigeria (Source: https://www.mapsofworld.com/).

\section{Methodology}

\subsection{Laboratory Determination of Boreholes water quality parameters}

One hundred and ten (110) boreholes were studied within the study area for the determination of the concentration of boreholes chemical parameters during wet and dry season respectively. The chemical parameters analyzed were EC, TDS, $\mathrm{HCO}_{3}, \mathrm{Na}, \mathrm{K}, \mathrm{Ca}, \mathrm{Mg}, \mathrm{Cl}-\mathrm{P}, \mathrm{NO}_{3}, \mathrm{SO}_{4}, \mathrm{Fe}, \mathrm{Zn}$. They were determined using standard procedure of American Public 
Health association [13] for determination of water quality parameters in the laboratory. EC and TDS were measured using Multi Portable Meter ( $\mathrm{HI}$ 9813-6). Titrimetric method were carried out to analyze $\mathrm{HCO}_{3}, \mathrm{Ca}, \mathrm{Mg}$ and $\mathrm{Cl}^{-}$. Ultraviolet visible spectrometer (Thermo Scientific Spectronic $20 \mathrm{D}^{+}$) was utilized in investigating $\mathrm{P}, \mathrm{NO}_{3}$, $\mathrm{SO}_{4}$. Iron and Zinc were determined using Atomic Absorption Spectrometer (Unicam 969 AA Model) which is dependent on wavelength and lamp current of the metals. Geographical locations of sampled boreholes were determined using Garmin GPS 72 receiver.

\subsection{Method for Fitting of Semi-Variogram Models}

The fitting of experimental results of boreholes water quality parameters into semi-variogram model were carried out using ARCGIS 10.1 software. The location points of the observed boreholes were tied with the results of water quality parameters for that point in microsoft excel sheet to form data base. Using geo-data base creation function of the software, the data in Microsoft excel was imported into the ArcMap 10.1 by clicking add data menu. From the file menu, the XY coordinates of the sampled points were added to create the surface for water quality parameters. Geostatistical analyst toolbar was used to first examine the distribution of observed borehole parameter data using histogram as shown in Figure 3 and transformation were applied where necessary for uniform distribution.

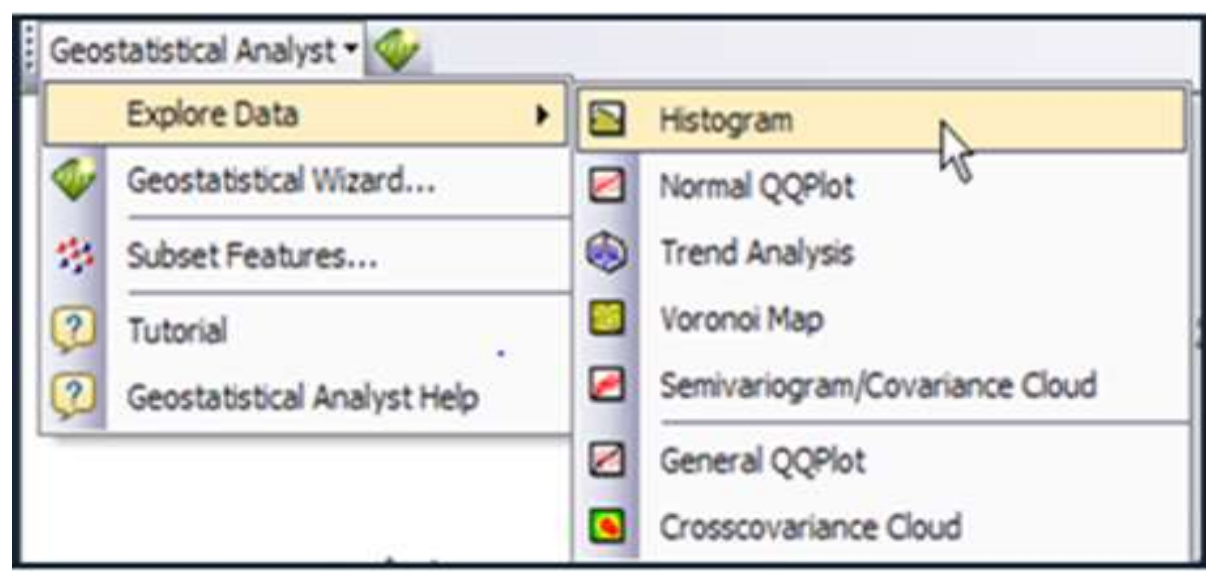

Figure 3 Geostatistical analyst toolbar and its features in the software.

Trends were also examined using trend analysis tool in the software to remove any trend pattern in the data set. Geostatistical wizard in the software was employed to fit semivariogram models and determine spatial dependency for prediction of concentration of other boreholes. Eleven (11) semivariogram models (circular, spherical, tetraspherical, pentaspherical, exponential, gaussian, rational quadratic, hole effect, K-bessel, J-bessel and stable) were fitted for each water quality parameter during dry and wet seasons to determine the best fitted model for the parameter through assessment of prediction errors using criterion already discussed earlier.

\section{Results and discussions}

\subsection{Experimental Results of Boreholes water quality parameters.}

The minimum and maximum concentration of laboratory results of the sampled boreholes are summarized in table 1 for wet and dry season. 
Table 1 Statistics results of boreholes chemical water quality parameters.

\begin{tabular}{|l|l|l|l|l|}
\hline \multirow{2}{*}{ Parameter(mg/l) } & \multicolumn{3}{|l|}{ Wet season } & \multicolumn{2}{l|}{ Min Season } \\
\cline { 2 - 5 } & Range & Max & Min & Max \\
\hline $\mathrm{EC}$ & 45.58 & 711.23 & 42.0 & 660 \\
\hline $\mathrm{TDS}$ & 22.88 & 369.91 & 20.1 & 329 \\
\hline $\mathrm{HCO}_{3}$ & 3.19 & 92.24 & 3.15 & 85.6 \\
\hline $\mathrm{Na}$ & 1.41 & 38.10 & 1.29 & 33.4 \\
\hline $\mathrm{K}$ & 0.09 & 5.02 & 0.11 & 4.24 \\
\hline $\mathrm{Ca}$ & 4.15 & 90.28 & 4.12 & 80.2 \\
\hline $\mathrm{Mg}$ & 0.11 & 2.48 & 0.11 & 2.13 \\
\hline $\mathrm{Cl}$ & 13.30 & 157.10 & 11.32 & 138.48 \\
\hline $\mathrm{P}$ & 0.03 & 1.08 & 0.01 & 0.97 \\
\hline $\mathrm{NO}_{3}$ & 0.01 & 4.78 & 0.02 & 3.59 \\
\hline $\mathrm{SO}_{4}$ & 0.15 & 8.19 & 0.11 & 6.92 \\
\hline $\mathrm{Fe}$ & 0.09 & 1.10 & 0.02 & 0.89 \\
\hline
\end{tabular}

The chemical parameters are within the maximum permissible limit recommend by World Health Organization (WHO) therefore, the concentration in boreholes are satisfactory for human consumption. This is in line with study carried out and reported by Obahiagbon and Ilori [3] on physic chemical studies of groundwater in Benin City.

\subsection{Fitted Semivariogram Models}

Using the observed boreholes water quality values for both seasons, eleven (11) semivariogram models (circular, spherical, tetraspherical, pentaspherical, exponential, gaussian, rational quadratic, hole effect, K-bessel, J-bessel and stable) were fitted for each water quality parameter. The prediction errors were also captured for validation. Table 2 shows semi variogram models depicting the prediction errors for EC parameter in wet season.

Table 2 Semivariogram models for EC parameter during wet season.

\begin{tabular}{|l|l|l|l|l|l|l|}
\hline S/N & Model Type & $\begin{array}{l}\text { Mean } \\
\text { Error } \\
\text { (ME) }\end{array}$ & $\begin{array}{l}\text { Root Mean } \\
\text { Square error } \\
\text { (RMSE) }\end{array}$ & $\begin{array}{l}\text { Mean } \\
\text { Standardized } \\
\text { error (MSE) }\end{array}$ & $\begin{array}{l}\text { Root mean } \\
\text { Squared } \\
\text { Standardized } \\
\text { error (RMSSE) }\end{array}$ & $\begin{array}{l}\text { Average } \\
\text { Standard } \\
\text { error } \\
\text { (ASE) }\end{array}$ \\
\hline 1. & Circular & 5.716 & 139.13 & 0.0092 & 0.9574 & 161.95 \\
\hline 2. & Spherical & 6.139 & 140.41 & 0.0021 & 0.9823 & 160.43 \\
\hline 3. & Tetrapherical & 6.093 & 141.30 & 0.0050 & 1.0021 & 159.05 \\
\hline 4. & Pentaspherical & 6.047 & 141.72 & 0.0080 & 1.0102 & 158.47 \\
\hline 5. & Exponential & 5.669 & 148.75 & 0.0061 & 1.1530 & 149.68 \\
\hline 6. & Gaussian & 6.500 & 134.53 & 0.0371 & 0.8772 & 168.53 \\
\hline 7. & Rational Quadratic & 6.835 & 147.19 & 0.0456 & 1.1322 & 154.19 \\
\hline 8. & Hole effect & 5.403 & 132.92 & 0.0517 & 0.8377 & 170.22 \\
\hline 9. & K-bessel & 6.953 & 144.34 & 0.0151 & 1.0282 & 159.84 \\
\hline 10. & J-bessel & 5.483 & 132.95 & 0.0511 & 0.8391 & 170.24 \\
\hline 11. & Stable & 7.298 & 140.96 & 0.0064 & 0.9726 & 163.79 \\
\hline
\end{tabular}


From Table 2, exponential model is the best fitted model for EC parameter in wet season. The RMSSE is 1.1530 which is approximately 1(one) indicating that standard errors are accurate. RMSE and ASE values (146.75 and 149.68 respectively) are the closest when compared with RMSE and ASE values of other models in table 2, depicting that the variability in prediction with the measured values were well assessed. With this criteria, models were assessed and cross validated for the best fitted for all the remaining chemical parameters for both seasons. Tables 3 and 4 are the best fitted models selected for each water quality parameter in wet season and dry season respectively.

Table 3 Best Fitted models for Borehole parameters and prediction errors for Wet season.

\begin{tabular}{|c|c|c|c|c|c|c|}
\hline \multirow{2}{*}{$\begin{array}{l}\text { Water } \\
\text { parameter } \\
(\mathrm{mg} / \mathrm{l})\end{array}$} & \multirow{2}{*}{$\begin{array}{l}\text { FITTED } \\
\text { SEMI VARIOGRAM } \\
\text { MODEL }\end{array}$} & \multicolumn{5}{|c|}{ PREDICTION ERRORS } \\
\hline & & ME & RMSE & MSE & RMSSE & ASE \\
\hline EC & Exponential & 5.669 & 148.75 & -0.061 & 1.1530 & 149.68 \\
\hline T.D.S & Exponential & 3.1901 & 83.2654 & -0.0597 & 1.1504 & 83.9477 \\
\hline $\mathrm{HCO}_{3}$ & Exponential & 1.017 & 19.901 & -0.073 & 1.148 & 22.599 \\
\hline $\mathrm{Na}$ & Exponential & 0.347 & 7.337 & -0.040 & 0.979 & 8.867 \\
\hline K & Exponential & 0.092 & 1.040 & -0.045 & 1.030 & 1.524 \\
\hline $\mathrm{Ca}$ & Rational Quadratic & 1.017 & 19.184 & -0.057 & 1.207 & 20.543 \\
\hline $\mathrm{Mg}$ & Exponential & 0.017 & 0.443 & -0.0077 & 1.198 & 0.492 \\
\hline $\mathrm{Cl}$ & Exponential & 1.331 & 29.811 & -0.040 & 1.128 & 30.937 \\
\hline $\mathrm{P}$ & Exponential & 0.031 & 0.250 & 0.002 & 0.869 & 0.379 \\
\hline $\mathrm{NO}_{3}$ & Exponential & 0.135 & 1.061 & -0.100 & 1.149 & 1.706 \\
\hline $\mathrm{SO}_{4}$ & Hole effect & 0.064 & 1.516 & -0.012 & 1.239 & 2.057 \\
\hline $\mathrm{Fe}$ & J-Bessel & 0.013 & 0.260 & -0.07 & 0.926 & 0.308 \\
\hline
\end{tabular}

In wet season, exponential model was the best fitted model for nine (9) water quality parameters namely EC, TDS, $\mathrm{HCO}_{3}$, $\mathrm{Na}, \mathrm{K}, \mathrm{Mg}, \mathrm{Cl}$ and $\mathrm{P}$. Hole effect model gave the best fitted for $\mathrm{SO}_{4}$; rational quadratic model is best fitted for Ca, and Jbessel model gave the best fit for Fe.

Table 4 Best Fitted model for Borehole parameters and prediction errors for Dry season.

\begin{tabular}{|l|l|l|l|l|l|l|}
\hline \multirow{2}{*}{$\begin{array}{l}\text { Water } \\
\text { parameter } \\
\mathbf{m g} / \mathbf{l} \mathbf{)}\end{array}$} & $\begin{array}{l}\text { FITTED } \\
\text { SEMI- VARIOGRAM } \\
\text { MODEL }\end{array}$ & MEEDICTION ERRORS & \multicolumn{2}{l|}{} \\
\cline { 4 - 7 } & Exponential & 4.304 & 131.82 & -0.062 & 1.149 & 128.72 \\
\hline $\mathrm{EC}$ & Exponential & 2.38 & 73.84 & -0.062 & 1.149 & 71.99 \\
\hline $\mathrm{T} . \mathrm{D} . \mathrm{S}$ & Exponential & 0.781 & 18.24 & -0.063 & 1.117 & 19.41 \\
\hline $\mathrm{Na}$ & Exponential & 0.281 & 6.711 & -0.044 & 1.000 & 7.824 \\
\hline $\mathrm{K}$ & Exponential & 0.046 & 0.832 & -0.035 & 1.039 & 1.050 \\
\hline $\mathrm{Ca}$ & Exponential & 0.793 & 16.546 & -0.037 & 1.084 & 17.735 \\
\hline $\mathrm{Mg}$ & Spherical & 0.015 & 0.374 & -0.064 & 1.087 & 0.418 \\
\hline $\mathrm{Cl}$ & Exponential & 0.952 & 26.88 & -0.032 & 1.076 & 27.41 \\
\hline $\mathrm{P}$ & Exponential & 0.031 & 0.188 & -0.029 & 1.065 & 0.331 \\
\hline $\mathrm{NO}_{3}$ & K-bessel & 0.117 & 0.824 & -0.105 & 1.162 & 1.290 \\
\hline $\mathrm{SO}_{4}$ & Hole Effect & 0.049 & 1.126 & -0.016 & 1.154 & 1.524 \\
\hline $\mathrm{Fe}$ & Hole effect & 0.0029 & 0.251 & 0.007 & 1.015 & 0.248 \\
\hline
\end{tabular}


In dry season, exponential model was the best model for eight (8) water quality parameters namely EC, TDS, HCO3, Na, $\mathrm{K}, \mathrm{Ca}, \mathrm{Cl}$ and $\mathrm{P}$. The Hole effect model fitted best for Fe and SO4. Spherical model fitted best for Mg and k-bessel model for NO3.

\subsection{Spatial dependency Results}

Fitted semi-variogram models chart for each of the water quality parameter provide information about the range, nugget and partial sill (model parameters) which are used to measure the degree of spatial dependency of sampled borehole points.

The fitted semi-variogram charts for the parameters are given in Figures $4 a-15 a$ for wet season (WS) and $4 b-15 b$ for dry season (DS) revealing the model parameters, i.e., the nugget, sill and partial sill.

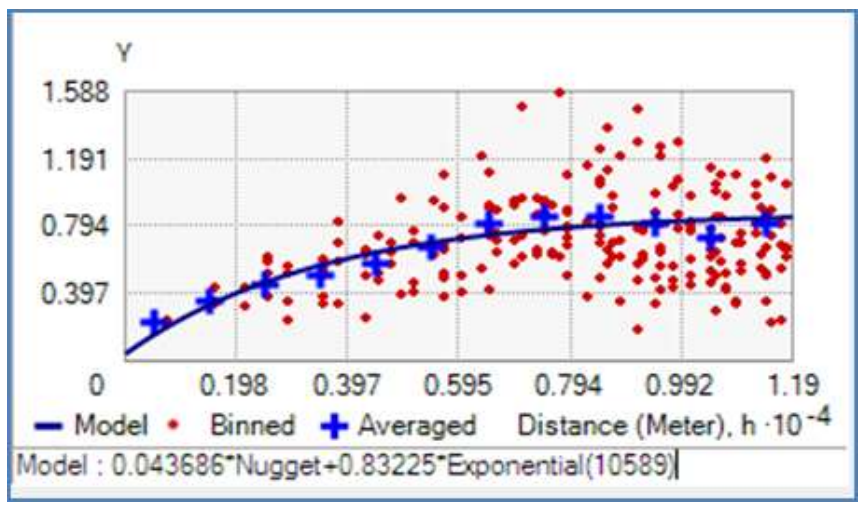

Figure 4a Electrical Conductivity (WS)

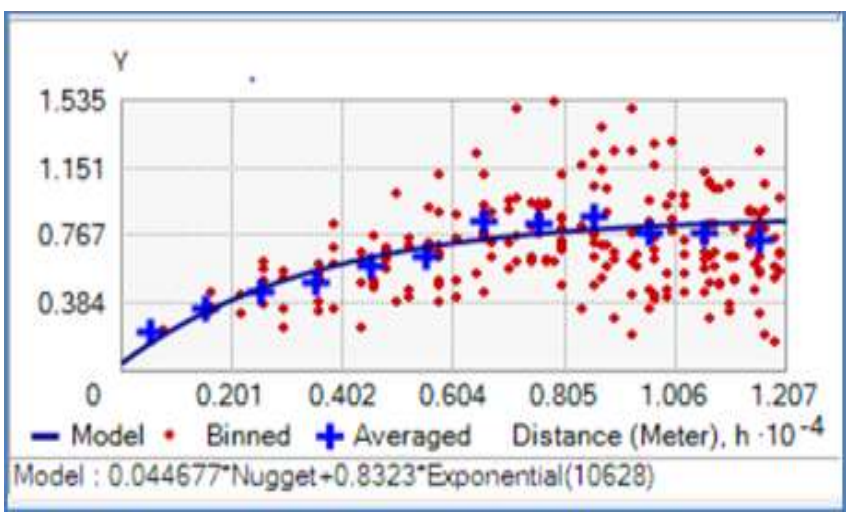

Figure 5a Total Dissolved Solid (WS)

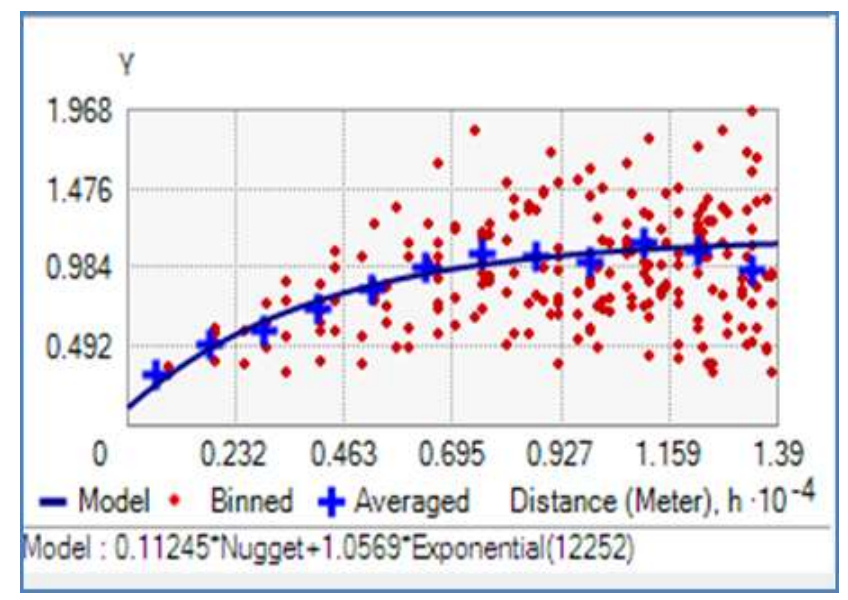

Figure 6a Bicarbonate (WS)

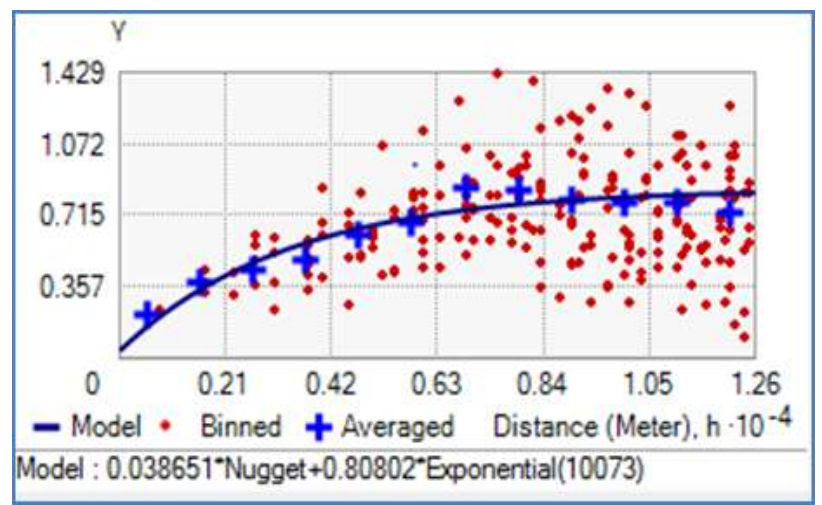

Figure 4b Electrical Conductivity (DS)

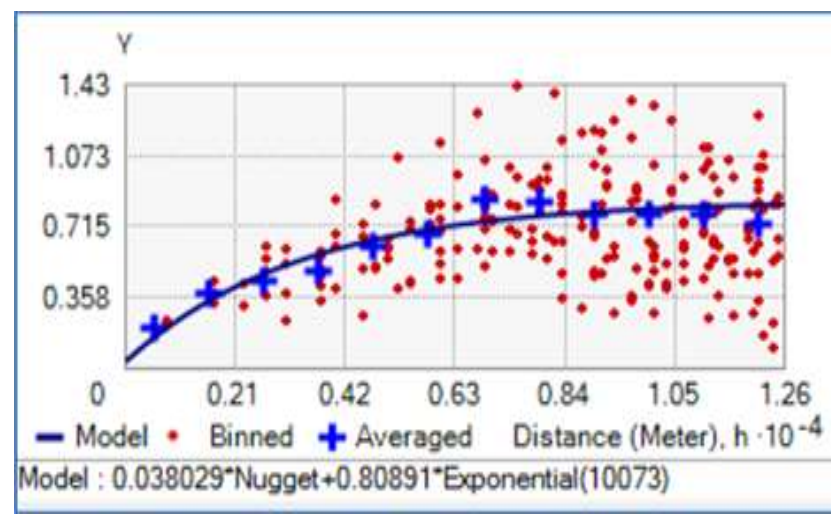

Figure 5b Total Dissolved Solid (DS)

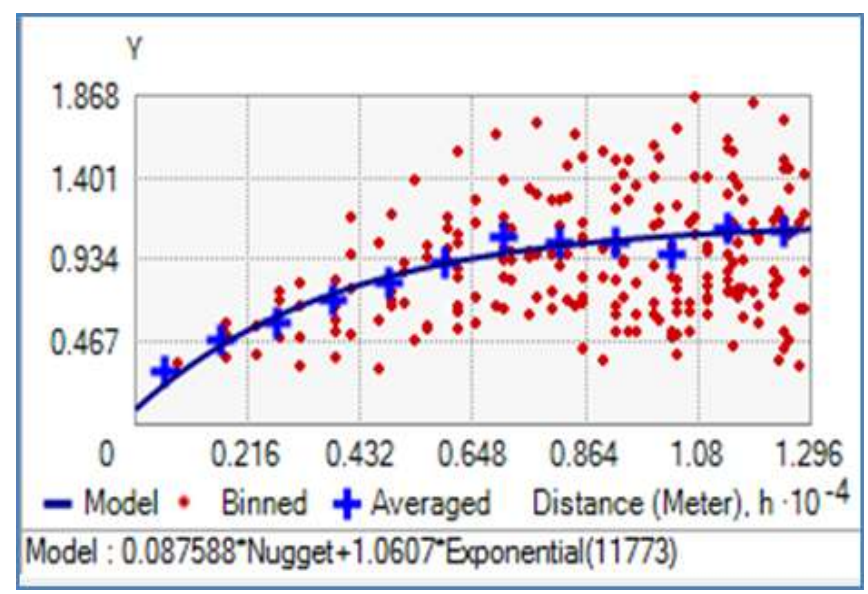

Figure 6b Bicarbonate (DS) 


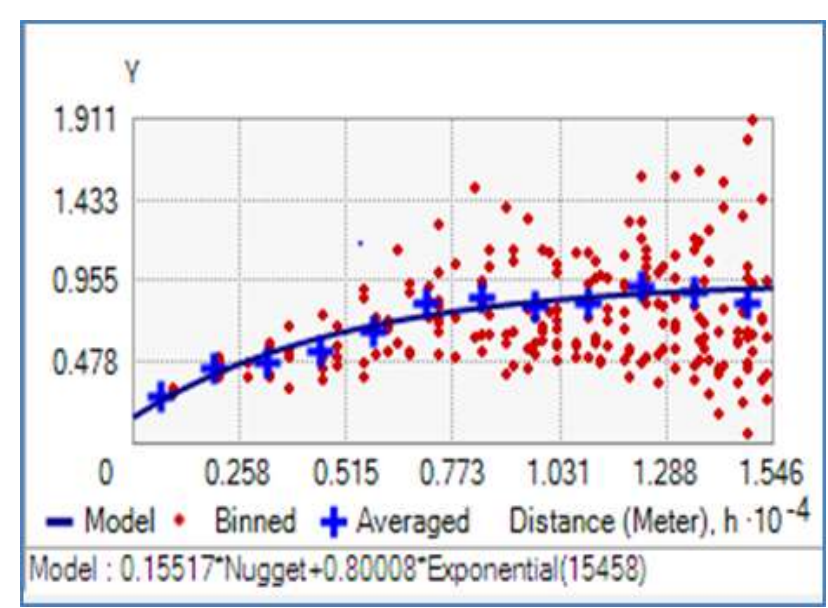

Figure 7a Sodium (WS)

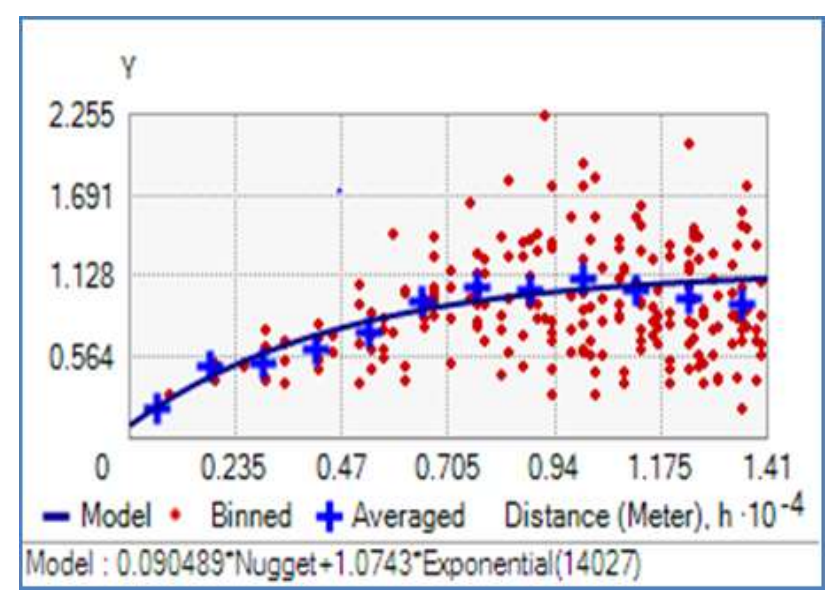

Figure 8a Potassium (WS)

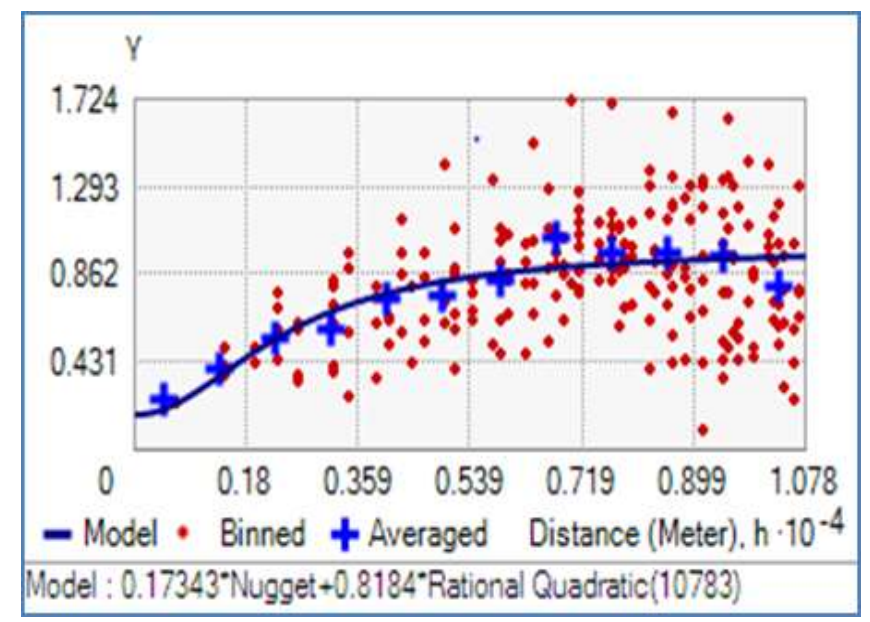

Figure 9a Calcium (WS)

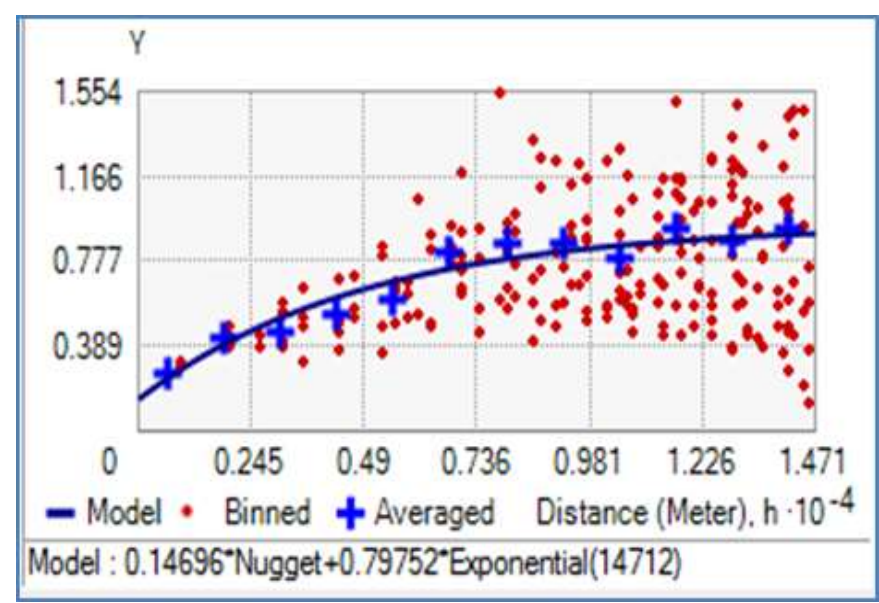

Figure 7b Sodium (DS)

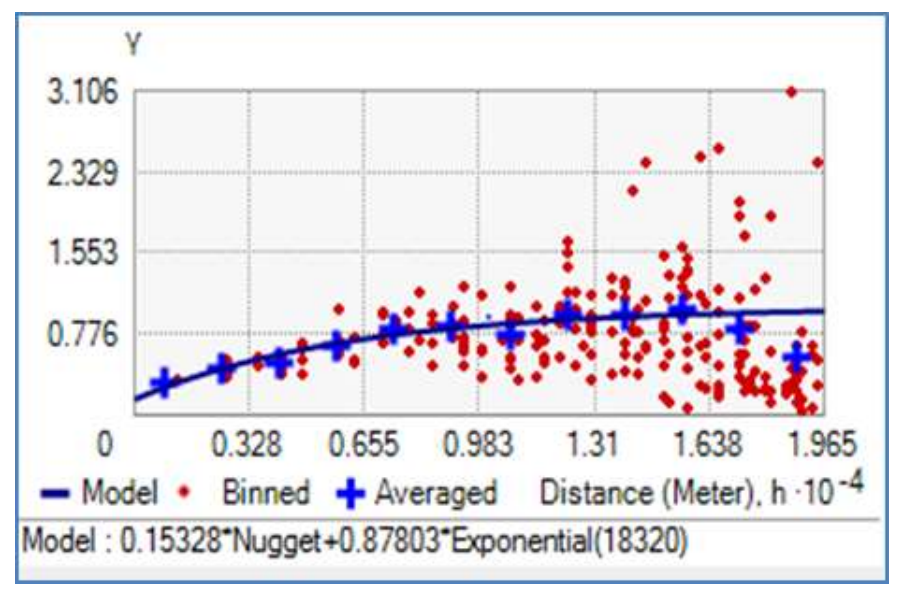

Figure 8b Potassium(DS)

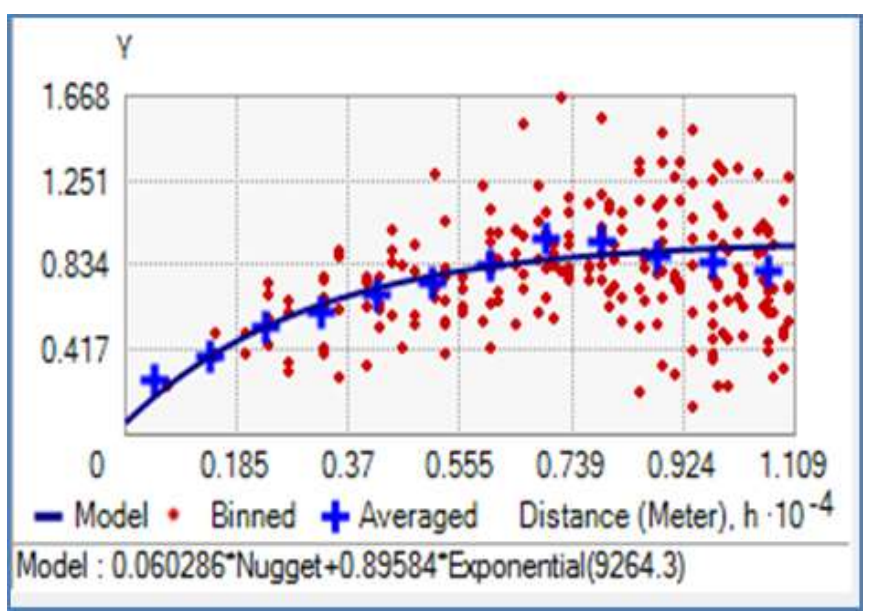

Figure 9b Calcium (DS) 


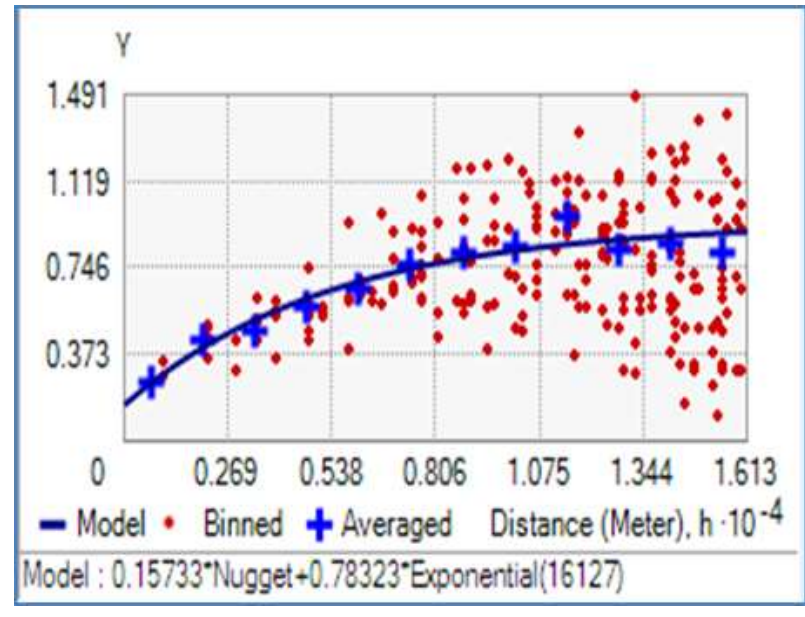

Figure 10a Magnesium (WS)

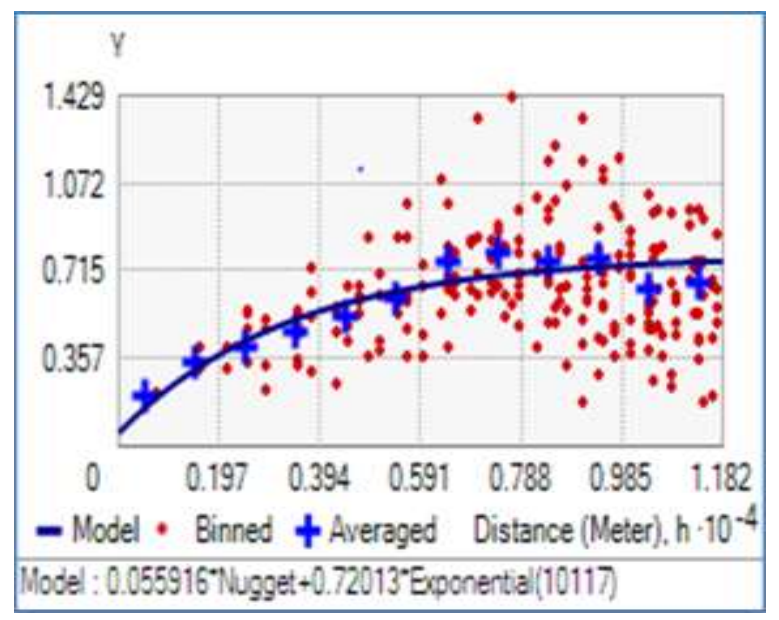

Figure 11a Chloride (WS)

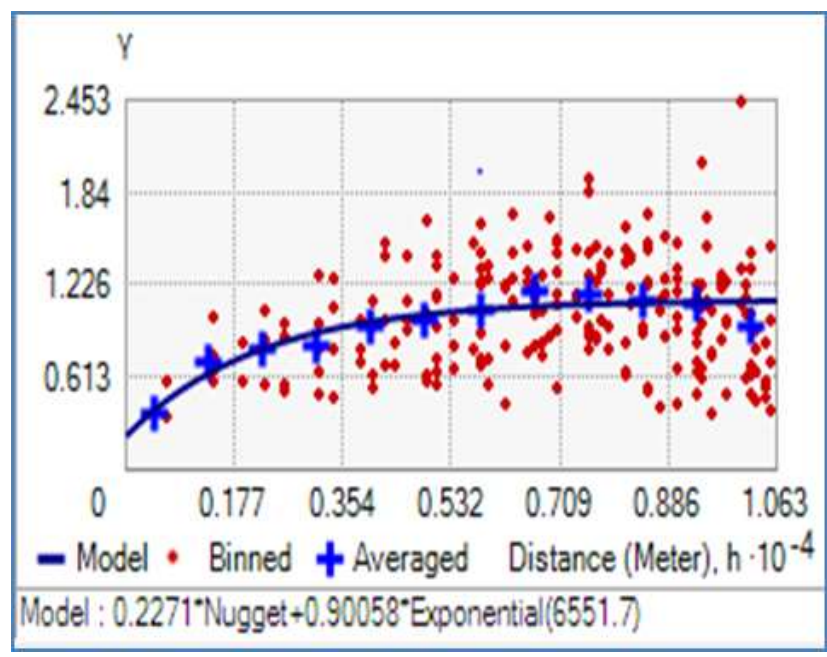

Figure 12a Phosphorus (WS)

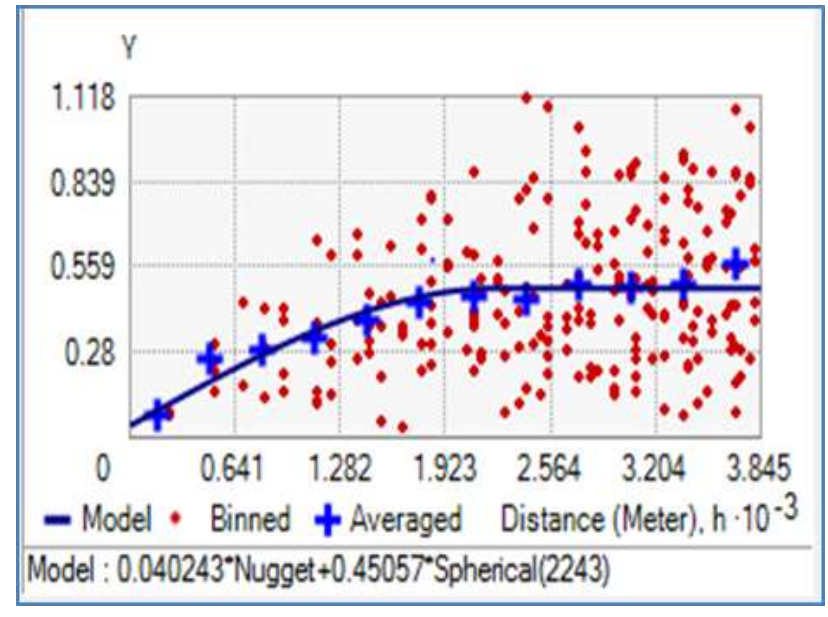

Figure 10b Magnesium (DS)

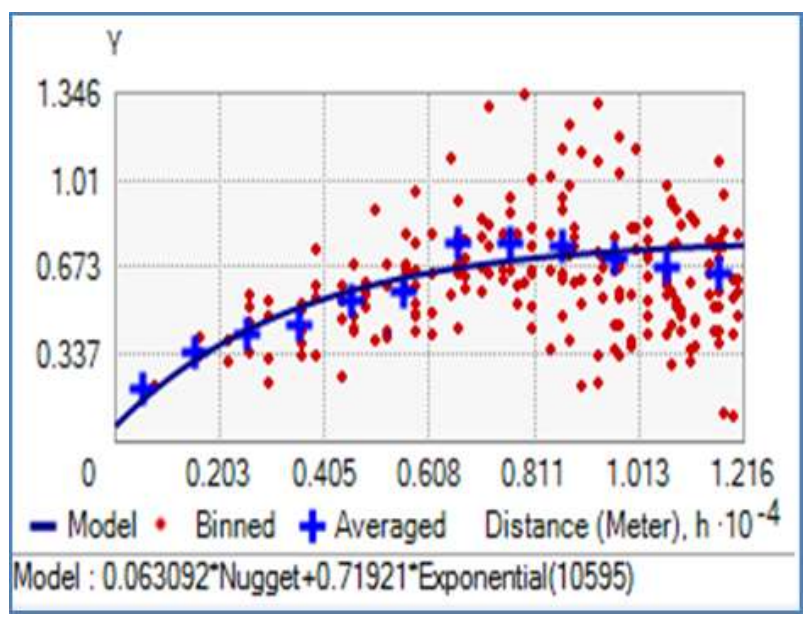

Figure 11b Chloride (DS)

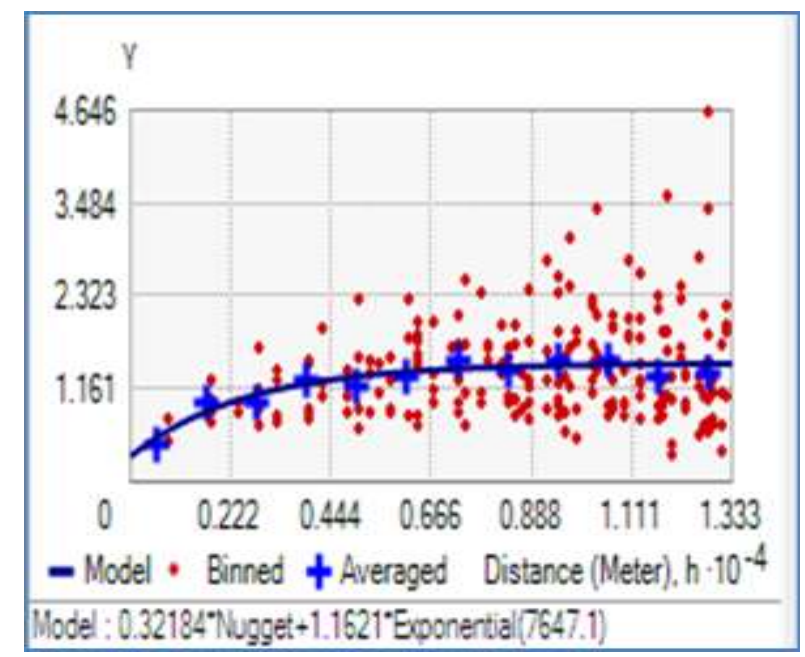

Figure 12b Phosphorus (DS) 


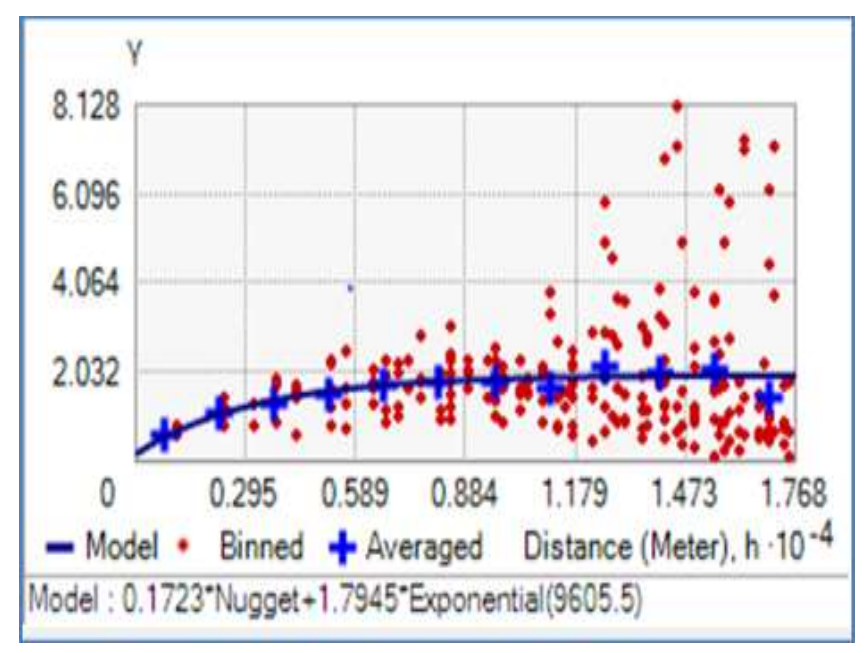

Figure 13a Nitrate (WS)

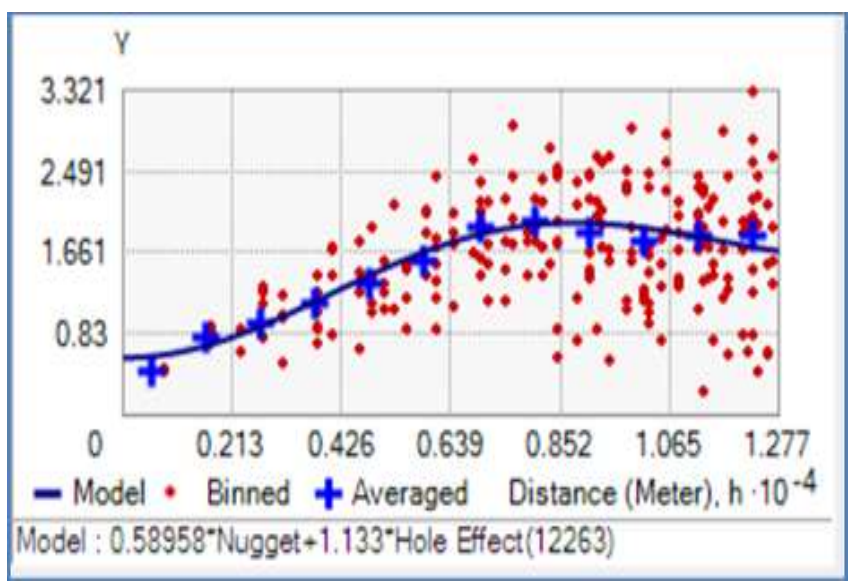

Figure 14b Sulphate (WS)

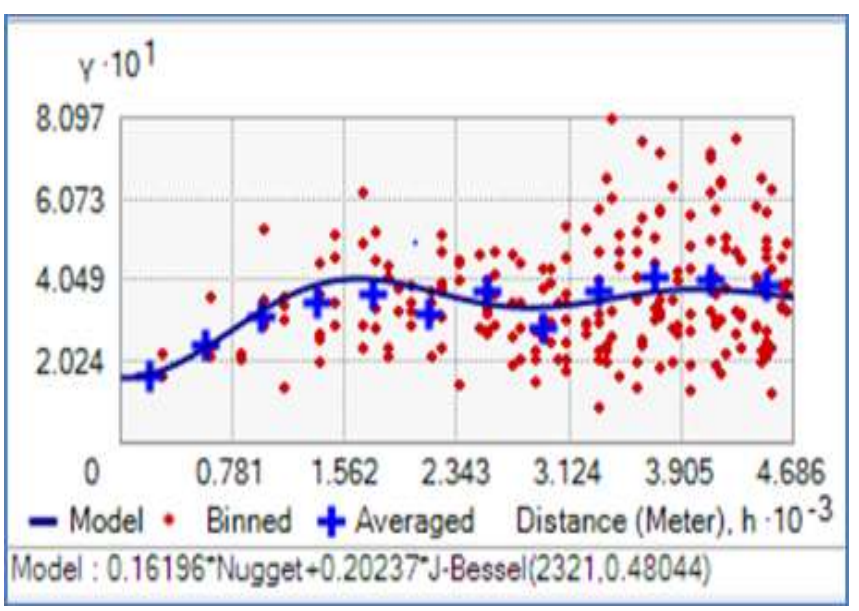

Figure 15a Iron (WS)

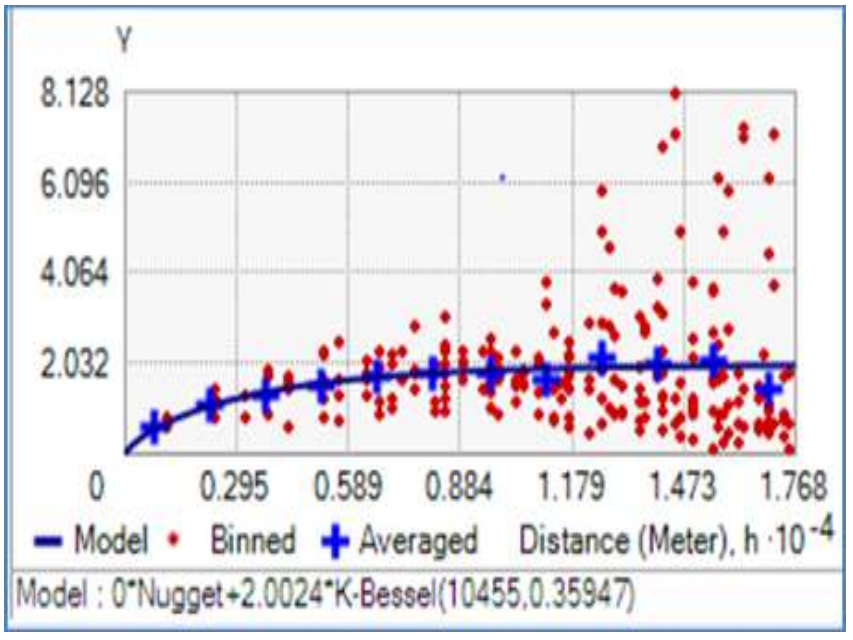

Figure 13b Nitrate (DS)

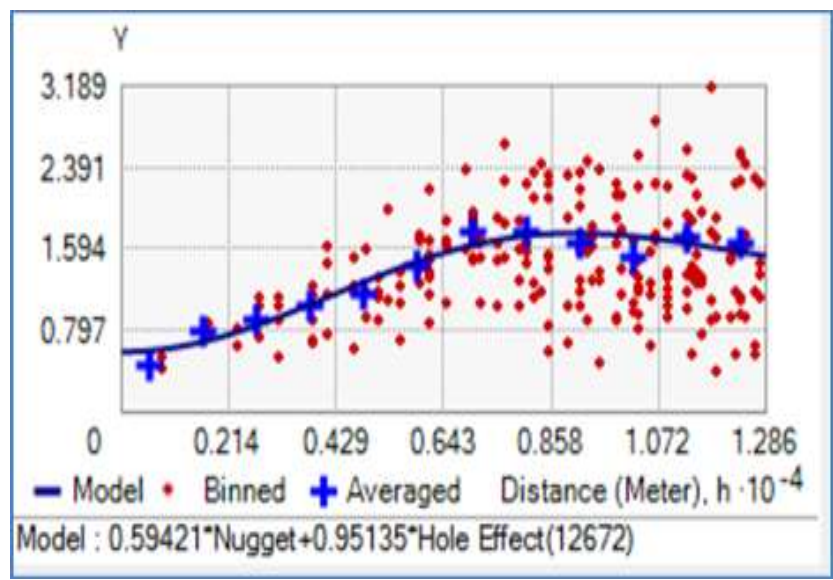

Figure 14b Sulphate (DS)

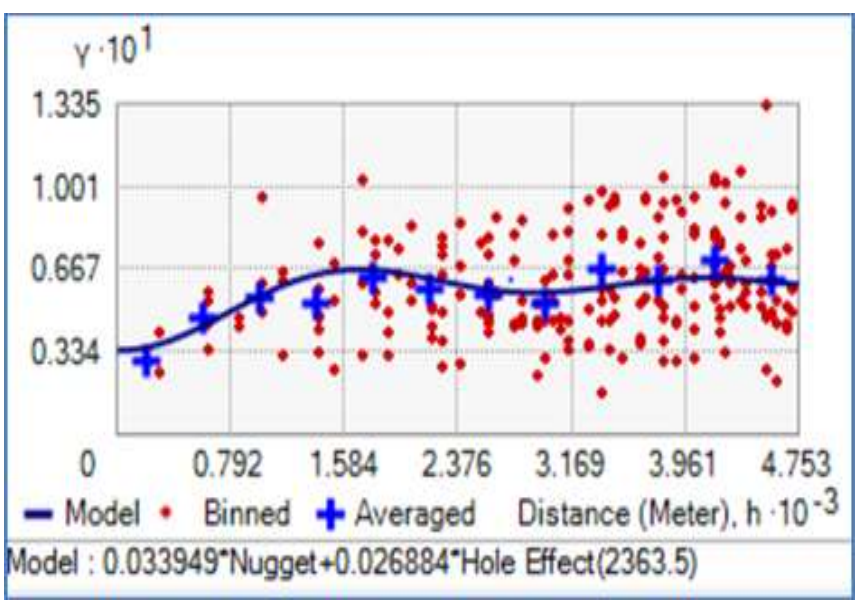

Figure 15b Iron (DS)

Figure $4 \mathrm{a}$ and $4 \mathrm{~b}$ showed semi-variogram exponential model chart for EC in wet season (WS) and dry season (DS) revealing the model parameters i.e., the nugget, sill and partial sill. The range value is 10589 , nugget (Cn) is 0.043686 and partial sill $(\sigma)$ is 0.83225 . The sill $(C)$ is the summation of nugget and partial sill depicted in equation 6 which equals 0.87594 . Therefore, the ratio of Nugget to Sill (Cn/c) for EC in wet season is $4.99 \%$ which is less than $25 \%$, thus signifying strong dependency [14]. If the ratio is between $25 \%$ and $75 \%$, the variable has moderate spatial dependence, and greater than $75 \%$, denotes weak spatial dependency $[6,7]$. 
The model parameters from the charts were utilized to calculate degree of spatial dependency summarized in Table 5 and 6 for wet and dry seasons respectively.

Table 5 Model Parameters and Degree of spatial dependency for wet season.

\begin{tabular}{|c|c|c|c|c|c|c|c|}
\hline $\begin{array}{l}\text { Water } \\
\text { parameter } \\
(\mathrm{mg} / \mathrm{l})\end{array}$ & Fitted Model & $\begin{array}{l}\text { Range } \\
\text { (a) }\end{array}$ & $\begin{array}{l}\text { Nugget } \\
\left(C_{n}\right)\end{array}$ & $\begin{array}{l}\text { Partial } \\
\text { Sill } \\
(\sigma)\end{array}$ & $\begin{array}{l}\text { Sill }(C)= \\
C_{n}+\sigma\end{array}$ & $\left(\frac{\boldsymbol{C}_{n}}{\boldsymbol{C}}\right) \%$ & $\begin{array}{l}\text { Degree of } \\
\text { spatial } \\
\text { Dependency }\end{array}$ \\
\hline EC & Exponential & 10589 & 0.043686 & 0.83225 & 0.87594 & 4.99 & Strong \\
\hline T.D.S & Exponential & 10628 & 0.044677 & 0.8323 & 0.87698 & 5.09 & Strong \\
\hline $\mathrm{HCO}_{3}$ & Exponential & 12252 & 0.11245 & 1.0569 & 1.16935 & 9.62 & Strong \\
\hline $\mathrm{Na}$ & Exponential & 15458 & 0.15517 & 0.80008 & 0.95525 & 16.24 & Strong \\
\hline $\mathrm{K}$ & Exponential & 14027 & 0.090489 & 1.0743 & 1.16479 & 7.77 & Strong \\
\hline $\mathrm{Ca}$ & Rational Quadratic & 10783 & 0.17343 & 0.8184 & 0.99183 & 17.49 & Strong \\
\hline $\mathrm{Mg}$ & Exponential & 16127 & 0.15733 & 0.78323 & 0.94056 & 16.73 & Strong \\
\hline $\mathrm{Cl}$ & Exponential & 10117 & 0.055916 & 0.72013 & 0.77605 & 7.21 & Strong \\
\hline $\mathrm{P}$ & Exponential & 6551.7 & 0.2271 & 0.90058 & 1.12768 & 20.14 & Strong \\
\hline $\mathrm{NO}_{3}$ & Exponential & 9605 & 0.1723 & 1.7945 & 1.9668 & 8.76 & Strong \\
\hline $\mathrm{SO}_{4}$ & Hole effect & 12263 & 0.58958 & 1.133 & 1.72258 & 34.23 & Moderate \\
\hline $\mathrm{Fe}$ & J-Bessel & 2321.0 & 0.16196 & 0.20237 & 0.36433 & 44.45 & Moderate \\
\hline
\end{tabular}

Table 6 Model Parameters and Degree of spatial dependency for dry season.

\begin{tabular}{|c|c|c|c|c|c|c|c|}
\hline $\begin{array}{l}\text { Water } \\
\text { parameter } \\
(\mathrm{mg} / \mathrm{l})\end{array}$ & Fitted Model & $\begin{array}{l}\text { Range } \\
\text { (a) }\end{array}$ & $\begin{array}{l}\text { Nugget } \\
\left(C_{n}\right)\end{array}$ & $\begin{array}{l}\text { Partial Sill } \\
(\sigma)\end{array}$ & $\begin{array}{l}\text { Sill (C) = } \\
C_{n}+\sigma\end{array}$ & $\left(\frac{c_{n}}{c}\right) \%$ & $\begin{array}{l}\text { Degree of } \\
\text { spatial } \\
\text { Dependency }\end{array}$ \\
\hline EC & Exponential & 10073 & 0.038651 & 0.80802 & 0.84667 & 4.57 & strong \\
\hline T.D.S & Exponential & 10073 & 0.038029 & 0.80891 & 0.84694 & 4.49 & strong \\
\hline $\mathrm{HCO}_{3}$ & Exponential & 11773 & 0.087588 & 1.0607 & 1.14829 & 7.63 & strong \\
\hline $\mathrm{Na}$ & Exponential & 14712 & 0.14696 & 0.79752 & 0.94448 & 15.56 & strong \\
\hline K & Exponential & 18320 & 0.15328 & 0.87803 & 1.03131 & 14.86 & strong \\
\hline $\mathrm{Ca}$ & Exponential & 9264 & 0.060286 & 0.89584 & 0.95613 & 6.31 & strong \\
\hline Mg & Spherical & 2243 & 0.040243 & 0.45057 & 0.49081 & 8.20 & strong \\
\hline $\mathrm{Cl}$ & Exponential & 10595 & 0.063092 & 0.71921 & 0.7823 & 8.06 & strong \\
\hline $\mathrm{P}$ & Exponential & 7647.1 & 0.32184 & 1.1621 & 1.48394 & 21.68 & strong \\
\hline $\mathrm{NO}_{3}$ & K-bessel & 10455 & 0.1000 & 2.0024 & 2.1024 & 4.76 & strong \\
\hline $\mathrm{SO}_{4}$ & Hole effect & 12672 & 0.59421 & 0.95135 & 1.54556 & 38.45 & Moderate \\
\hline $\mathrm{Fe}$ & Hole effect & 2363 & 0.033949 & 0.02688 & 0.06083 & 55.81 & Moderate \\
\hline
\end{tabular}

From Table 5 and 6 summarily, EC, TDS, HCO3, Na, K, Ca. Mg, Cl, P, and NO3 showed strong spatial dependency in both seasons with $\mathrm{Cn} / \mathrm{C}$ ratio $<25 \%$ while SO4, and Fe exhibited moderate dependency between $25 \%$ - $75 \%$ in both seasons as well. In the study conducted by Karami et al, [15] on groundwater modelling, EC and TDS indicated moderate spatial dependence while $\mathrm{Cl}, \mathrm{Na}+, \mathrm{SO} 42-$, Total hardness revealed strong spatial dependency. However, it revealed that groundwater quality are spatially dependent. 


\section{Conclusion}

Laboratory results of boreholes water quality parameters investigated revealed the conformity of the level of concentration of parameters within the recommended limits set for human consumption by World Health Organization. Semi-variogram models are an efficient geostatistical tools and have been utilized to evaluate spatial structure of boreholes water quality parameters in Benin City for the purpose of determining boreholes water quality of unmeasured locations within the area. Exponential model was mostly used for eight water quality parameters in both seasons. EC, TDS, HCO3, Na, K, Ca. Mg, Cl, P, and NO3 showed strong spatial dependency in wet and dry seasons indicating the strength of spatial correlation of the boreholes water quality parameters as a function of distance for accurate predictions of unmeasured locations. However, Fe and SO4 exhibited moderate spatial dependency. Constant monitoring of the boreholes water quality can be gingered through this technique that reduced the bottlenecks and cumbersome procedure of sampling the entire boreholes within the study area. This will ensure continuous protection from health risks of consuming contaminated water and directly will also save money, time and resources. Application of other interpolation techniques and Geographic Information System (GIS) can confidently be employed to create a continuous surface and produced spatial distributions map of boreholes water quality parameters in Benin City.

\section{Compliance with ethical standards}

\section{Acknowledgments}

We sincerely appreciate Mr Nicholas Uwadia, Energy Centre, University of Benin, Edo State, Nigeria for his unalloyed support in data analysis using ARCGIS software.

\section{Disclosure of conflict of interest}

The authors wish to state that there is no conflict of interest in this work.

\section{References}

[1] Bohling G. Introduction to Geostatistics and Variogram Analysis. 2005.

[2] GI systems and Science. Spatial Interpolation and Surface Analysis. Accessed August. 2012.

[3] Obahiagbon FI, Ilori GE. Commercial Groundwater in Benin City; Elemental Constituents. International Journal Chemistry. 2011; 21(1): $1-7$.

[4] Balakrishnah P, Saleem A, Mallikarjun ND. Groundwater Quality Mapping Using Geographic Information Systems (GIS): A case study of Gulbarga City, Karnataka, India. African Journal of Environmental Science and Technology. 2011; 5(12): 1069- 1084.

[5] El-Hoz M, Mohsen A, Laaly A. Assessing Groundwater Quality in a Coastal Area Using the GIS Technique. 6th International Conference on water Resources in Mediterranean Basin (WATMED6), 10-12, Sousse, Tunisia. 2013.

[6] Chang KT. Introduction to Geographic information Systems. Seventh edition. McGraw-Hill Companies, Inc., 1221 Avenue, America, New York, NY 10020. 2014.

[7] Liu D, Wang Z, Zhang B, Song K, Li X, Li J, Li F, Duan H. Spatial Distribution of Soil organic carbon and Analysis of Related factors in croplands of the black soil region, Northeast China. Agriculture Ecosystem Environmental Journal. 2006; 113: $73-81$.

[8] ESRI. ArcGIS Geostatistical Analyst Tutorial: Statistical Tools for data exploration, Modeling, and Advanced Surface Generation, ESRI white papers, August. 2010; 19.

[9] SAS/STAT (R). User's Guide, SAS Institute Inc, Cary, NC, USA. 2010.

[10] Nas B. Geostatistical Approach to Assessment of Spatial Distribution of Groundwater Quality" Polish Journal of Environmental Studies. 2009; 18(6): 1073-1082.

[11] Vasanthavigar M, Srinivasamoorthy K, Vijayaragavan K, Ganthi RR, Chidambaram S, Anandhan P, Manivannan R, Vasudevan S. Application of Water Quality Index for Groundwater Quality Assessment: Thirumanimuttar subbasin, Tamilnadu, India. Environmental Monitoring Assessment. 2010; 171: 595-609. 
[12] Erah PO, Akujieze CN, Oteze GE. The Quality of Groundwater in Benin City: A baseline study on inorganic Chemicals and microbial contaminants of Health importance in boreholes and open wells. Tropical Journal of pharmaceutical research, Benin City, Nigeria. 2002; 1(2): 75 - 82.

[13] American Public Health Association (APHA). Standard Methods for the the Examination of Water and Wastewater, 20th edition. American Water Works Association, Water Environment Federation, Washington, DC. 1999.

[14] Essington ME. Soil and Water Chemistry: An Integrative Approach. 2005.

[15] Karami S, Madani H, Katibeh H, Marj AF. Assessment and modeling of the groundwater hydrogeochemical quality parameters via geostatistical approaches. Applied Water Science. 2018; 8(23). 